\title{
Success or failure? Making sense of outcomes in a public sector change project
}

\author{
Grete Hagebakken, Trude Høgvold Olsen* (D) and Elsa Solstad \\ School of Business and Economics, UiT The Arctic University of Norway, P.O.Box 1063, NO-9480 Harstad, Norway \\ ${ }^{\star}$ Corresponding author. Email: trude.h.olsen@uit.no
}

(Received 13 August 2019; accepted 25 August 2020)

\begin{abstract}
The most common method of assessing outcomes of change projects is to compare the final outcomes with predefined goals and conclude that the project has been a success, or more commonly, a failure. We question whether such simple conclusions pay due respect to complex processes. In this paper, we apply a sensemaking perspective to explore how and when outcomes of change projects are assessed. We report from a longitudinal case study of a project in the Norwegian public sector that was initiated to suggest and implement changes in response to major challenges in the health sector. We found outcome narratives in all project phases, including those not based on change objectives. The study contributes to the literature by suggesting that outcome narratives are continuously constructed throughout change projects and that competing outcome narratives can co-exist, be reinforced or be merged over time.
\end{abstract}

Key words: organizational change; change outcomes; success and failure; projects; public sector

\section{Introduction}

The spirit of our age is characterized by expectations for continuous change, rapid decisionmaking and a need to make quick judgements about success and failure. In modern Western economies, one-third of all work is carried out in projects (Schoper, Wald, Ingason, \& Fridgeirson, 2018) and planned organizational change is increasingly implemented as projects (Pádár, Pataki, \& Sebestyén, 2017; Pollack, 2017). This indicates that projects can be seen as a trend in how to cope with change pressure. Projects are highly goal-oriented and are perceived as suitable for solving complex problems. The dominant way of measuring success and failure in the traditional project management literature is to compare outcomes with predetermined goals (Papke-Shields, Beise, \& Quang, 2010; PMI (Project Management Institute), 2013). Goal attainment is also a central topic in the change management literature (Hughes, 2011). When goal attainment is used to assess change project outcomes, projects that fulfil the predetermined goals are labelled as successes and projects that fail to reach the goals are labelled as failures (Patton, 2015; Thomas, George, \& Rose, 2016; Vaara, 2002).

While the simplicity of goal attainment is intriguing, it is problematic in the assessment of change project outcomes in the public sector. It is challenging to assess the attainment of goals that are ambiguous, contested and continuous, which is often the case in the public sector (Denis, Langley, \& Rouleau, 2005). These characteristics of public sector goals do not exempt managers from the expectations to reach clear conclusions from their change efforts. However, the goal attainment perspective runs the risk of defining good change projects as failures because they can be assessed on the wrong basis and at the wrong time. We therefore need alternative theoretical perspectives to guide our understanding of how change project outcomes are

(c) Cambridge University Press and Australian and New Zealand Academy of Management 2020. This is an Open Access article, distributed under the terms of the Creative Commons Attribution licence (http://creativecommons.org/licenses/by/4.0/), which permits unrestricted re-use, distribution, and reproduction in any medium, provided the original work is properly cited. 
interpreted. We suggest that a sensemaking perspective (Maitlis \& Christianson, 2014; Weick, 1995) addresses the problems of using goal attainment as the only definition of project outcomes and enables outcome accounts to be viewed as constructed in complex and social processes where competing perceptions about outcomes co-exist.

The study reported in this paper is a single exploratory and longitudinal case study from the public sector in Norway. The case was a project initiated to suggest and implement changes in response to major challenges in the municipal health sector. The sensemaking perspective allowed us to explore the following research questions: (1) How are outcome narratives constructed? (2) When do they emerge? Our study challenges the assumptions of the goal attainment perspective that outcomes are only measured against predetermined goals and only at the end of a change project. We contribute to the discussion of change project outcome assessments by arguing that sensemaking is a promising theoretical perspective to answer the questions of how outcome narratives are constructed and when they appear.

The paper is structured as follows: first, the literature on sensemaking and change outcomes is reviewed and discussed. Second, the empirical setting and the research methods are described. Third, empirical findings are presented and discussed. In the conclusion, the theoretical and practical implications of the paper are discussed.

\section{Literature Review: How are Outcome Narratives Constructed?}

In this section, we review how the project management literature and the change management literature describe outcomes. We discuss challenges associated with the dominant goal attainment perspective to understand how and when outcome narratives are constructed in a public sector context and suggest that a sensemaking perspective provides a more comprehensive understanding of our research questions.

The most common way of defining the value of the outcome of a change initiative is to examine whether the organization has reached its objectives (Thomas, George, \& Rose, 2016; Vaara, 2002) or the 'publicized rationale for the change' (Hughes, 2011, p. 456). We understand this as a goal attainment perspective where outcomes are assessed based on predetermined goals (Patton, 2015). Goal attainment sparks success narratives, while failure to achieve the goals produces failure narratives. Even though organizational change research has increasingly taken contextual complexities, ambiguities and uncertainties into consideration (e.g., Anzola-Román, Bayona-Sáez, \& García-Marco, 2019; Hughes, 2011; Pettigrew, Woodman, \& Cameron, 2001), accounts of change outcomes are still simplistically portrayed as either successes or failures (Thomas, George, \& Rose, 2016; Vaara, 2002). One example of such simplistic portrayal of change outcomes is Beer and Nohria's (2000, p. 133) claim that 'the brutal fact is that about 70 percent of all change initiatives fail'. Similar conceptualizations of failure also apply in other areas (Singh, Corner, \& Pavlovich, 2007).

The goal attainment perspective seems intriguingly simple as it is well suited to explore outputs and outcomes of a change project and provides an understanding of outcome narratives as constructed around pre-determined goals. The perspective builds on assumptions such as consensus about clear goals. However, it falls short of explaining outcome narratives when goals are ambiguous, contested and continuous, which is the case in the public sector (Denis, Langley, \& Rouleau, 2005), and it does not explain how (Patton, 2015) these outcome narratives are constructed. The increased use of projects in the public sector (Schoper et al., 2018) and the emphasis on clear goals in project work (Papke-Shields, Beise, \& Quang, 2010; PMI (Project Management Institute), 2013) underestimate the challenges of the goal attainment perspective on public sector change project outcomes. Ambiguous goals make it difficult to evaluate change outcomes as 'objective and polarized states' (Fincham, 2002, p. 3) because ambiguity triggers subjective interpretations (Weick, 1995) of both goals and outcomes. Contested goals suggest several diverging opinions and perceptions about change outcomes (Davis, 2014). The assumption that outcomes can be 
objectively assessed contradicts findings suggesting that leaders and change agents value the outcomes of change more positively than change recipients (Doyle, Claydon, \& Buchanan, 2000; Vaara, 2002) and that the same change project may be simultaneously described as a success and as a failure (Fincham, 2002; Vaara, 2002). Continuous goals raise the question of when change outcomes can be assessed. The goal attainment perspective suggests that change outcomes can be readily assessed at the end of the change process. However, it is not always easy to determine when an organizational change is fully implemented (Buchanan et al., 2005; Jacobs, 2002), suggesting that it may be difficult to find an appropriate time to evaluate change outcomes.

We argue that it is important to develop our understanding of the process of outcome narrative construction in the public sector for two reasons. First, the characteristics of goals in the public sector are ill-suited to guide quick judgments about success or failure based on predetermined goals. Second, a number of stakeholders have interests in the outcomes of change projects in public services but their perspectives may differ and trigger diverse outcome interpretations. Thus, change outcomes can be viewed as socially constructed (Buchanan, Addicot, Fitzgerald, Ferlie, \& Baeza, 2007). A sensemaking perspective (Weick, 1995) can remedy some of the challenges of the goal attainment perspective in analysing how actors construct accounts of change outcomes (Balogun, 2006). The sensemaking perspective focuses our attention on the social processes by which outcome narratives are constructed (Fincham, 2002; Sage, Dainty, \& Brookes, 2013, 2014; Vaara, 2002) rather than objective assessments of goal attainment. In organizational change studies, sensemaking has been applied to explore and understand how actors come to understand the purpose and processes of change (e.g., Balogun \& Johnson, 2004; Mantere, Schildt, \& Sillince, 2012). Fewer studies focus on the sensemaking of change outcomes (see Balogun, 2006 for a notable exception). The term 'sensemaking' describes a:

'process, prompted by violated expectations, that involves attending to and bracketing cues in the environment, creating intersubjective meaning through cycles of interpretation and action, and thereby enacting a more ordered environment from which further cues can be drawn' (Maitlis \& Christianson, 2014, p. 67).

The first part of the sensemaking definition concerns 'attending to and bracketing cues in the environment' (Maitlis \& Christianson, 2014, p. 67). From a goal attainment perspective, goals are the only cue for sensemaking, and outcomes would be categorized as either success or failure. A sensemaking perspective will broaden the search for cues that spark the construction of outcome narratives. This is important because the literature points to several issues that could serve as such cues. For example, change projects may produce unintended and unanticipated outcomes (Balogun, 2006) which will not be identified from a goal attainment perspective simply because outcomes are assessed against predetermined goals. Another example described in the literature is that change projects may be small in terms of resources (Söderlund, 2012), but have ambitious objectives that boost expectations of the project's results (Thomas, George, \& Rose, 2016) and increase the probability of concluding with change failure. Even though projects are delimited in scope and time as a means of reducing complexity, the outcomes of projects are likely to be assessed not only according to project outcomes but in terms of organizational outcomes. This could blur the categorization of outcomes as successes or failures.

The second part of the sensemaking definition focuses on 'creating intersubjective meaning through cycles of interpretation and action' (Maitlis \& Christianson, 2014, p. 64). While the goal attainment perspective suggests that meaning is created through calculation rather than interpretation, the sensemaking perspective helps unravel the social processes whereby the outcome narratives are constructed. Projects typically involve people with different backgrounds to solve complex tasks. Projects are thus social settings where different actors could attend to different cues and categorize these cues differently. When people work closely together, the interpretation of project and change goals may be facilitated or negotiated. Thus, outcome narratives are results of social 
processes where cues and brackets are subject to discussion and negotiation. However, projects regulate actors' access to different sensemaking arenas where outcome narratives are tested and negotiated, and this could result in the emergence of competing and co-existing outcome narratives (Brunsson, 2007; Fincham, 2002; Sage, Dainty, \& Brookes, 2013, 2014; Vaara, 2002). Even though making sense of outcomes is a collective act (Maitlis, 2005), this does not necessarily mean that all actors share the same account of change outcomes at all times. We would expect, however, that outcome narratives align across actors over time as meaning is negotiated and renegotiated (Balogun, 2006; Balogun \& Johnson, 2004). Thus, the sensemaking perspective complements the goal attainment perspective by focusing attention on how outcome narratives emerge in a social setting where interpretations are shared and contested and action assessed. This is important because it highlights the intersubjective dimension of making sense of outcomes when goals are ambiguous, contested and continuous. It also acknowledges the processual nature of outcome assessment and suggests that outcome narratives may emerge at various times as meaning is constructed and renegotiated as individuals notice and categorized cues about outcomes.

The third part of the sensemaking definition concerns 'enacting a more ordered environment' (Maitlis \& Christianson, 2014, p. 64). From a goal attainment perspective, outcomes are neatly bracketed in a well-ordered dichotomy of success or failure based on predetermined goals. As we have discussed, the characteristics of public sector goals suggest less ordered change project outcomes. The results of sensemaking processes are accounts and action (Maitlis, 2005). Accounts can be presented as narratives that are 'temporal, discursive constructions that provide a means for individual, social and organizational sensemaking and sensegiving' (Vaara, Sonenshein, \& Boje, 2016, p. 496). A narrative 'reveals not only who is involved and what they are doing but also the meanings that they are constructing in the process' (Maitlis \& Christianson, 2014, p. 81). Perceived change project outcomes could be a cue that triggers sensemaking processes, as well as the result of sensemaking processes. This suggests that sensemaking unfolds as a process (Balogun \& Johnson, 2004; Maitlis \& Christianson, 2014; Maitlis, 2005; Sonenshein, 2010; Weick, 1995) in which actors continuously construct outcome narratives.

The sensemaking perspective will thus be helpful in understanding who constructs outcome accounts, how and when. This is important because it allows us to explore how the characteristics of the public sector context are reflected in the outcome narratives.

\section{Research Setting and Research Methods \\ Research setting}

The project reported in this paper is based on the healthcare service of a Norwegian municipality. The project had three objectives that indicated high expectations: (1) to provide better services to meet future needs, (2) to improve municipal health and social services, and (3) to ensure budget balance.

The municipality provides both centre-based and home-based services to all inhabitants in need of such services regardless of age. When the project started in 2014, the percentage of the population above 80 years of age was increasing, implying an increased demand for healthcare services. The healthcare services employed about 680 full-time staff and were allocated around $40 \%$ of the total municipal budget. Cost reductions in this sector would thus have a significant impact on the economic situation in the municipality. The municipality had a high level of operational expenses and a large debt ratio compared to similar municipalities, and it faced new and changing tasks due to recent national policy reforms in healthcare. These challenges set the stage for this project.

\section{Data collection}

Our goal was to gain insight into sensemaking processes by change agents involved in the same project. The research team followed the project closely from August 2014 to December 2017. 
A longitudinal approach gave the study adequate coverage over time (Rosenbaum, More, \& Steane, 2017). The access allocated to the research also allowed for data triangulation (Bryman \& Bell, 2015; Easterby-Smith, Thorpe, \& Lowe, 2002; Müller \& Söderlund, 2015; Pettigrew, 1990). The main data sources were archival records, observations, informal conversations and interviews, which are the most common data collection methods for sensemaking studies (Maitlis \& Christianson, 2014). The documents were analysed in order to reflect opinions and events in the project in real time. When observing meetings, researchers took extensive notes on what was said by whom. After every observation, the researchers compared and contrasted the notes to reach a shared understanding of the observed discussions. The real-time observation data was helpful in understanding how the actors made sense of what was happening in the project, what they had achieved and not achieved, where to go next and how they related to the project work.

The archival records and observations provided a rich contextual understanding before we carried out the semi-structured interviews with all five members of the project group in June 2016, about 18 months into the project. The project group members were the deputy chief municipal officer, the project manager (municipal advisor) and three middle managers, all of whom were health professionals. The steering committee was not involved in the daily operation of the project. We therefore found it sufficient to observe the meetings in the steering committee. The purpose of the interviews was to explore how the participants made sense of the project progress. The interview guide included the following themes: (1) the purposes and objectives of the project, (2) the interviewees' role in the project, (3) relevant events that had affected the project, (4) the interviewees' perceptions of factors that had worked well, (5) any challenges they had encountered, (6) their perceptions of the results they had obtained so far and (7) their thoughts on how to proceed. The interviews lasted for approximately 60 minutes. All interviews were recorded and transcribed verbatim, and were then sent to the informants for validation. Data collection continued after the interviews and involved more observations, conversations and documents. The research project was reported to and approved by the Data Protection Official for Research. Figure 1 summarizes the data on which the analysis was based.

\section{Data analysis and validity}

Data were analysed in four steps. First, following project and change management literature that differentiates between project phases (Armenakis \& Bedeian, 1999; Bakari, Hunjra, \& Niazi, 2017; Kloppenborg \& Opfer, 2002), we defined three project phases (start up, execution and closure, see Figure 1) using temporal bracketing (Langley, 1999) by identifying important events over time. Despite the critique of instrumental, sequential and prescriptive phase models (e.g., Hughes, 2016), the analytical use of phases is beneficial in identifying when change outcome narratives appear and how the narratives are constructed.

The important events in this case were the annual presentation and discussion of the project in the municipal council at the end of every year of the project period. We defined the start of the project start-up phase as the large meeting where the first version of the consultancy report was presented in October 2014. Because the municipality required some amendments to the first consultancy report, the start-up phase dragged on and ended with a municipal council meeting in December 2015. The start-up also included the establishment of the project organization and three meetings in the project group. The project execution phase started after the municipal council meeting in December 2015 and ended with a municipal council meeting in November 2016. Project closure is the phase where project results should materialize and be interpreted. This phase started with the report to and discussions in the municipal council in December 2016 and lasted until the municipal council meeting a year later, when the results from the project were presented again.

In the second step, for each of these three phases, quotations from the interviews that illustrated how the informants made sense of change outcomes over time were extracted before being compared and contrasted with archival and observational data, such as notes from 


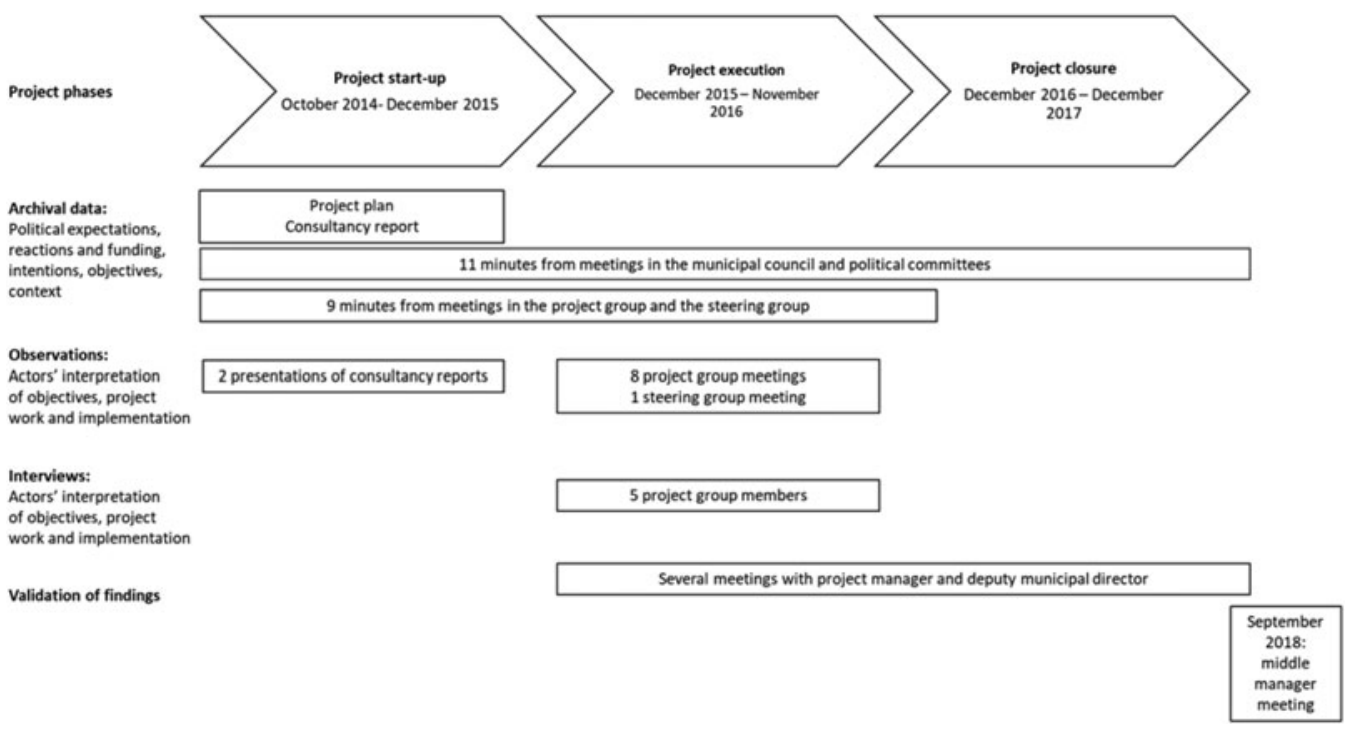

Figure 1. Data collection

meetings in the project group, meetings in the steering group and presentations of consultancy reports. The third step was data reduction, which started with categorization of the data. The categorization was data-driven, resembling the process of constructing first-order concepts (Gioia, Corley, \& Hamilton, 2013) (see Table 1). The coding and analysis progressed as follows: first, we discussed categories, then each researcher coded the data according to the categories and finally the researchers discussed the data and categories. The research team cooperated closely in the coding and categorization process, and the resulting categories emerged from detailed discussions. In the fourth step, first-order concepts were related to the literature by linking the data to theoretical issues. This resulted in four second-order constructs: project objectives, project organization, project progress (see Table 1) and outcome narratives (see Figure 2). Fragmented accounts of project objectives, project organization and project progress contributed to the construction of different outcome narratives emerging at different project phases, and expressed in various parts of the organization. We found both failure and success narratives. In addition, we found the spin-off narratives that diverged from the dichotomous outcome narratives of success and failure found in the literature. Even though failure and success narratives described in the literature are tied to goal attainment, we found other baselines for these narratives. The data analysis was validated at various points in time in meetings with the deputy chief municipal officer and the project manager. They confirmed that our analysis was an accurate description of their understanding of change project outcomes.

\section{Findings}

This section is organized according to the three phases of project start, project execution and project closure. After we have presented data in each of the phases, we will sum up the outcome narratives that emerged in each phase.

\section{Project start}

The data show a complex, top-heavy project organization. The project group consisted of five members, while the steering group had nine members. All these members were central actors 
Table 1. Data analysis

\begin{tabular}{|c|c|c|c|}
\hline $\begin{array}{l}\text { Descriptions of } \\
\text { the project in } \\
\text { the data }\end{array}$ & Start-up & Execution & Closure \\
\hline $\begin{array}{l}\text { Project } \\
\text { objectives }\end{array}$ & $\begin{array}{l}\text { Support of project purpose } \\
\text { 'we have to be more } \\
\text { efficient' (manager at } \\
\text { initial meeting) } \\
\text { Ambitious but unclear and } \\
\text { broad } \\
\text { Different descriptions } \\
\text { in documents } \\
\text { 'And perhaps it wasn't } \\
\text { so obvious to us either } \\
\text { what we were going to } \\
\text { do.' (I3) }\end{array}$ & $\begin{array}{l}\text { Blurry boundaries between } \\
\text { project and day-to-day } \\
\text { operations } \\
\text { 'The project has just been a } \\
\text { part of the normal working } \\
\text { day' (I2) }\end{array}$ & $\begin{array}{l}\text { Too ambitious in terms of } \\
\text { available resources } \\
\text { Chief municipal } \\
\text { officer's report to } \\
\text { municipal council } \\
\text { November } 2017\end{array}$ \\
\hline $\begin{array}{l}\text { Project } \\
\quad \text { organization }\end{array}$ & $\begin{array}{l}\text { Diverse change agents } \\
\text { formally represented in } \\
\text { the project } \\
\text { Broad involvement } \\
\text { Top heavy }\end{array}$ & $\begin{array}{l}\text { Daily work prioritized } \\
\text { 'The participants are } \\
\text { responsible both for } \\
\text { day-to-day operations and } \\
\text { for taking the project } \\
\text { forward, but they're mostly } \\
\text { concerned with day-to-day } \\
\text { operations' (I3) } \\
\text { Project tasks moved from } \\
\text { project to daily operations } \\
\text { 'The difficult discussions } \\
\text { are not out in the open... } \\
\text { The important discussions } \\
\text { take place in the back } \\
\text { rooms' (I2) }\end{array}$ & $\begin{array}{l}\text { Project organization } \\
\text { faded but discussions } \\
\text { continued in } \\
\text { established meetings } \\
\text { in the permanent } \\
\text { organization }\end{array}$ \\
\hline Project progress & $\begin{array}{l}\text { Loss of faith in the project } \\
\text { as a way of solving the } \\
\text { problems: } \\
\text { 'I'd describe it as } \\
\text { organizational faking' } \\
\text { (I2) }\end{array}$ & $\begin{array}{l}\text { Lack of progress } \\
\text { 'We haven't had any major } \\
\text { breakthrough at all yet' (I5) } \\
\text { Irregular meetings } \\
\text { New, more delimited projects } \\
\text { initiated } \\
45 \text { projects defined (council } \\
\text { meeting November 2016) }\end{array}$ & $\begin{array}{l}\text { Reached objective of } \\
\text { balancing the budget. } \\
\text { Projects of more } \\
\text { limited scope linked to } \\
\text { focal project initiated }\end{array}$ \\
\hline
\end{tabular}

in the municipal organization, including some politicians in the steering group. The main arguments for this broad involvement (top managers, union representatives, politicians, administrative staff and middle managers) were based on the need to abide by the rules of the game for municipal processes and to create project support and legitimacy.

The observation data identified a reference group for the project that was not described in the project documents. This reference group consisted of all seven middle managers reporting to the deputy chief municipal officer, three of whom were members of the project group. This added to the complexity of the project organization, as discussions about project objectives and project work took place in both the established management teams and in the formal project group. Some of the informants explained that at times it was difficult to know which hat to put on, because they attended different meetings with the same colleagues where they discussed the same things.

The data showed that the politicians, the administrative leaders and many of the middle managers supported the overall project purposes. The meeting where the first consultancy report was presented to all leaders and middle managers showed commitment to the project initiative in the sense that there was agreement that something had to be done. Comments we heard in the 


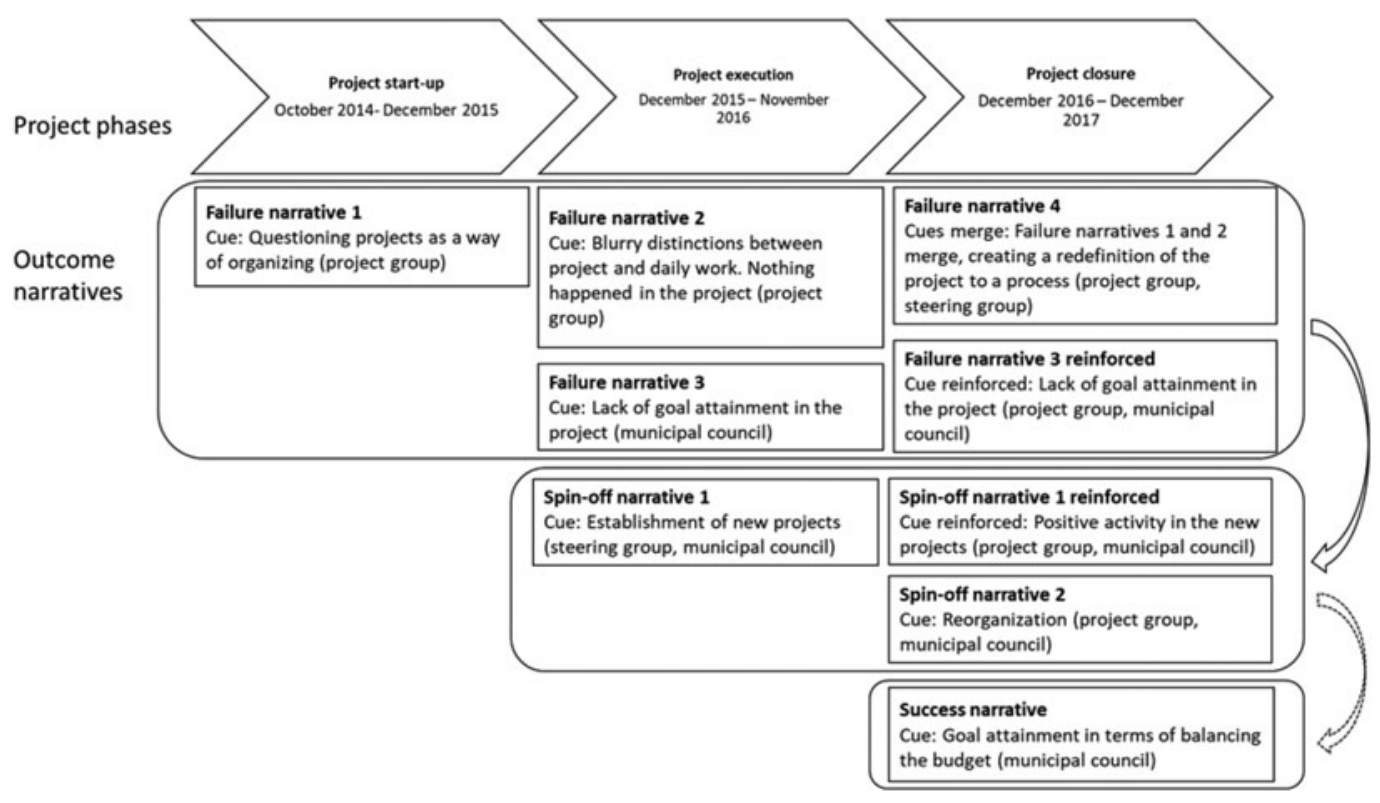

Figure 2. Findings

meeting included 'We have not been good enough'; 'We have to be more efficient'; and 'We have to cooperate more across results units and departments'.

The project objectives described in the consultancy report were ambitious and included specific suggestions for future work in the project group. To some extent, these objectives were consistent with those described in the project documents. For example, the project documents had a stated aim of cost reduction, and the consultancy report suggested specific cost-reducing measures. However, in other aspects, the consultants' conclusions diverged from the project objectives. For example, the consultancy report suggested specific changes in the organizational structure, while the project group chose not to emphasize structural change in the start-up phase. The interview data confirmed findings from the consultancy report and observations. For instance, the consultancy report suggested both short-term and long-term goals for the project. The short-term goal was to reduce expenditure in line with the budget. The long-term goal was to have the same costs as comparable municipalities and to reach robust and sustainable services in the future. Several of the informants also explained that the project had two objectives: one in the short term and one in the long term.

There were two objectives in the project. One was the challenges connected to how we spend the money ... and the second was to prepare the healthcare sector for the challenges in the future. (Informant 1)

This concerns both ... getting financial control today, and facilitating how to deliver adequate services in the future. (Informant 3)

The informants perceived these project objectives as ambiguous and this sparked sensemaking processes. The project group discussed the project objectives at several meetings:

And perhaps it wasn't so obvious to us either what we were going to do. (Informant 3) We had to find out ... what was wrong in our sector. (Informant 1) 
As the project group made sense of the project objectives in the first project group meetings, we observed that they agreed that something had to be done. However, some of them were sceptical about projects as a way to solve problems. Some of the informants felt that the establishment of a project was just a symbolic way of addressing fundamental problems in the municipality. Based on their previous experience with similar projects, they described the new project as:

... organizational faking ... when you have a problem in this organization, you don't work to solve the problem, you just order a consultancy report. (Informant 2)

Ritual practices regularly take place in our organization. This is just another project to add to this routine. Nothing special... (Informant 5)

\section{Outcome narratives in the project start}

Even though we found support for the main purpose of the change initiative, we were surprised to find signs of an emerging failure narrative in the project group at this early stage of the process (Failure narrative 1, see Figure 2). Failure narrative 1 was not based on goal attainment even though sensemaking in the project group focused on project objectives. Instead, the failure narrative was based on interpretations of previous experiences with project work.

\section{Project execution}

The main activities for this phase were to decide on an implementation strategy and to start implementing tasks of priority. We expected the project group to work towards realizing the project objectives decided in the municipal council meeting in December 2015. However, the data show that the project group struggled to separate the project work from their day-to-day operations. Project group meetings sometimes became arenas for expressing frustrations about daily operations, rather than arenas for discussing strategies to deal with these problematic issues, which was the main goal of the project. The observation data showed that discussions in the project group meetings moved back and forth between the project itself and the challenges of daily operations. The interviewees confirmed this:

The project has just been a part of the normal working day. (Informant 2)

The participants are responsible both for day-to-day operations and for taking the project forward, but they're mostly concerned with day-to-day operations. (Informant 3)

In addition, all project group members experienced substantial pressures in their jobs that led them away from the project. Examples of these pressures included the need to handle crises and media pressure and to follow up on political decisions. Some of the informants emphasized how varying political signals affected the project:

I don't know if the politicians are satisfied because they want quality, but at the same time, it's not supposed to cost anything. (Informant 2)

We must really cut down on services for many of the clients to cover our expenditure on the few clients who get media attention. In addition, the politicians follow this up both in the media and in their meetings. It means that quality is going to be significantly worse for a large proportion of the clients and it's mainly the elderly who are affected. (Informant 3)

These quotations clearly show that politicians expected the administration to cut costs and increase the level and quality of services at the same time. Even though the project was initiated to cut costs, politicians instructed the administration to increase the quality of health services for specific groups, causing costs to rise. This put the managers and the project members in a difficult position, because the expectations for their work were constantly changing. 
Project meetings were irregular. Sometimes there were weekly meetings, while at other times several months passed between meetings. Although traditional project management literature is clear about the temporary time frame of projects, this particular project did not have a formal deadline at the start:

When the project goes on for such a long time, it loses its importance. (Informant 4)

I think the project is a hidden secret in the municipality. (Informant 4)

Even though discussions in the project group meetings served to underscore the importance of the project goals, the group members recognized that the necessary measures to fulfil these goals were comprehensive, complex, costly and time-consuming. Because this was not in harmony with the cost-reducing goals, few decisions came out of the discussions. Consequently, a perception emerged among the project members that nothing was happening in the project:

I don't know if there have been any significant events. ... It's not very goal-oriented. (Informant 2)

I spend a couple of hours, and I have no trouble to spare the time for these meetings. But I don't get the impression that the meetings are good workshops. (Informant 4)

We haven't had any major breakthrough at all yet. (Informant 5)

The perception over time that nothing was happening had implications for the project group members' commitment to the project. The interview data indicated that the lack of commitment surfaced in different ways.

At the last steering group meeting, the chief municipal officer did not show up, the head of human resources did not attend. (Informant 1)

They [project group] aren't prepared at all. Actually, no results. (Informant 1)

There's no commitment to the project, other than what I experience and see myself as part of a group that meets and talks, before I leave and return to work. (Informant 4)

The difficult discussions are not out in the open ... The important discussions take place in the back rooms. (Informant 2)

The challenges of ambitious goals and poor progress were addressed through discussions in the steering group and in the project group. Our observation data from the steering group meeting in June 2016 illustrated a plan to prioritize between goals and sub-projects. For example, the deputy chief municipal officer clearly articulated to the politicians: 'We cannot do everything at the same time'. How to prioritize was also the main issue in a project meeting in November 2016, when the deputy chief municipal officer summarized project goals and accomplishments so far. The discussion that followed sparked an outcome narrative that did not align well with either success or failure. The project group summarized their results to date by pointing to a number of old and new projects. Some old projects were seen as important to realizing the purpose of this project. In addition, a number of new projects of more limited scope were presented and discussed.

At the municipal council meeting in November 2016, the project was presented and discussed. The message was that the project had not achieved the main objective of balancing the budget. This was explained by a lack of resources and unforeseen challenges. Still, some achievements were highlighted. As part of the process of making sense of the mandate, 45 smaller projects had been described as necessary to reach the main goal, and it was stated that five of them would now have priority: (1) rehabilitation, (2) examining the necessity of two employees working together for security reasons, (3) motivating part-time staff to take full-time jobs, (4) the financing model and (5) a reorganization of the health sector. This was an important decision because it made the project easier to define. 


\section{Outcome narratives in the execution phase}

In this phase, we identified two new failure narratives constructed around different baselines and by various actors. Failure narrative 2 (see Figure 2) was constructed around the understanding of blurry boundaries between project work and everyday work, because discussions about the project took place both within the project organization and in established meetings in the permanent organization. These circumstances led to key actors losing faith in the project as a tool for organizational change. Failure narrative 3 (see Figure 2) emerged in the municipal council meeting in November 2016. This failure narrative was based on the lack of goal attainment. In addition, we observed another outcome narrative in the political process leading up to the municipal council meeting in November 2016. Spin-off narrative 1 (see Figure 2) highlighted a potential for success by focusing on several new but more delimited projects.

\section{Project closure}

During the project closure phase, the project group and the steering group ceased holding meetings, and the municipality started to label the endeavour a long-term process instead of a project. The deputy chief municipal officer and the project manager still had important roles in planning and implementing strategies and continued discussions with middle managers in established meetings in the permanent organization.

In the summer of 2017, local media and policy documents from the municipal council announced a reorganization of the health service. A reorganization was one of the recommendations from the consultancy report from 2014, but the project group had excluded this from their work. In informal discussions with the project manager in the autumn of 2017, we gained the impression that this reorganization project was a spin-off. This spin-off project was considered to be an important step towards better health care services, according to the project manager.

In a document where the chief municipal officer reported to the municipal council meeting in November 2017, project results were described as successful in many ways. The document stated that the main goal of balancing the health services budget was achieved 3 years after project start. In addition, there was positive activity in seven smaller projects (spin-offs). In spite of the success, the chief municipal officer noted that the capacity of the organization was strained. Therefore, it was important to focus on the seven spin-off projects that had been initiated and to prioritize resources to conclude these projects.

\section{Outcome narratives in the closure phase}

The closure phase was characterized by a changed view of the project. The project group and the steering group seemed to give up the project and started to refer to the change endeavour as a 'process' in a report to the municipal council. This reflects Failure narratives 1 and 2. Giving up the project was a powerful symbol of failure, see Failure narrative 4 (Figure 2). In another way, this could be viewed as an adaptation to a complex reality where project organization is only one of many tools for promoting successful change processes. At the same time that the project 'disappeared', a success narrative emerged in the municipal council meeting of November 2017. The success narrative was based on goal attainment in terms of balancing the budget, which was one of the three goals of the project. In addition, Spin-off narrative 1 was reinforced and a new spin-off narrative emerged (see Figure 2). Thus, in the project closure phase, competing outcome narratives co-existed.

\section{Discussion}

Our research questions targeted two aspects of outcome narratives: How are they constructed and when do they emerge? From a goal attainment perspective, actors assess the outcomes of a change project at the end of the project as they compare the outcomes with the predetermined goals of 
the project and consider it a success if the goals are met or a failure if they are not met. Our findings do not fit well with this description. In this section, we discuss when and how outcome narratives emerged in our study, showing the benefits of the sensemaking perspective to enhance understanding of how individuals attend to cues, bracket information, interpret this with others and try out actions in efforts to construct a more ordered environment that explains the outcome of the change process.

We found that outcome narratives emerged in all phases of the change project (see Figure 2), not just at the end. In line with the goal attainment perspective, we found that goal attainment was a cue for outcome narratives categorized as failure (Failure narrative 3) and as success (Success narrative). Interestingly, the success narrative emerged at the end while failure narratives emerged at all stages. Our labelling of the outcome narratives reflects the dichotomous bracketing of cues suggested by the goal attainment perspective. These labels reflect how the involved actors described outcomes, and suggest that there is a pressure to deliver clear answers even though goals, process and outcomes are complex. The failure narratives parallel the stories of failed projects (Thomas, George, \& Rose, 2016) and failed organizational change initiatives (Hughes, 2011).

However, our findings contradict the goal attainment perspective in three ways. First, we identified other cues than goal attainment that triggered sensemaking of outcomes early in the project (Failure narratives 1 and 2). These cues include previous experience with project work to solve complex challenges, blurry distinctions between the project and daily work and a sense that nothing happened in the project. Thus, the social construction of outcome narratives took place in the project group as they attended to cues, not only in this particular project, but in their joint previous experiences of working with ambiguous and continuous goals. This suggests that when goals are ambiguous and continuous, outcome narratives are constructed but the baselines are more than goal attainment. This also means that failure narratives could emerge even though goals are attained, and that success narratives could emerge even though goals are not met. Thus, the findings question our understanding of failure and success. This is important because the political dimension is strong in public organizations. The stories of $70 \%$ failure (Beer \& Nohria, 2000) are misleading in such situations. When something has been called a failure, nobody will want to be associated with it. This is problematic because ambiguous and continuous goals reflect important challenges in the public sector that have to be addressed.

Second, our findings challenge the dichotomous understanding of outcomes as either success or failure. The spin-off narratives resemble findings in other studies that projects give birth to other projects (Forssell, Fred, \& Hall, 2013) but they also nuance the impression of categorizing change project outcomes as dichotomous. The spin-off projects varied in size and complexity, from the total re-organization of the municipal healthcare service to human resources projects targeting the challenges of an excessive number of part-time staff. Despite some differences, the spin-off projects had more operationalized objectives than the original project. It is intriguing that a new spin-off narrative (Spin-off narrative 2) appeared in the project closure phase. There are at least two possible explanations for this, both rooted in the characteristics of public sector goals (Denis, Langley, \& Rouleau, 2005). First, goals concerning improvements in health care service delivery are continuous. Even though a particular project ends, the challenges the project was intended to target are often permanent. Second, some goals are ambiguous and contested. This implies that stakeholders' wishes and needs to be associated with some form of success could be addressed by launching new projects with more explicit goals.

Third, we identified dynamic interconnections between the apparently competing outcome narratives, which add to the complexity of the understanding of outcomes. We found that cues were reinforced (Failure narrative 3 and Spin-off narrative 1) and merged (Failure narrative 4) over time. In addition, the spin-off narratives seem to connect the failure and success narratives (see the arrows in Figure 2). Even though the failure narratives seemed to dominate across the project phases, the cues for failure were addressed through processes of interpretation and re-interpretation of goals. The actors involved seemed to refuse to accept failure and searched 
for new ways to target the main challenges. We see this particularly in relation to the reports to the steering committee and to the municipal council that initiated and funded the change project. The spin-off narratives and the success narrative could be explained by stakeholders' efforts to frame the project as a (potential) success in order to tell funders that the project was worthy of further funding.

Our findings suggest that the construction of intersubjective meaning of outcomes is better described as cycles of interpretation and action (Maitlis \& Christianson, 2014) than as objective assessments of attainment of pre-determined goals. We identified two processes where actors created intersubjective meaning. Inspired by Balogun and Johnson (2005), we have labelled the first process 'reinforcement'. By reinforcement we mean that some outcome narratives were strengthened over time as they were shared by other stakeholders and as various actions triggered new cues about progress. As Figure 2 illustrates, some of the outcome narratives were reinforced in later project phases. As outcome narratives were shared in other parts of the organization than where they emerged, the narratives were reinforced. For example, Failure narrative 3 emerged in the municipal council in project execution and spread to the project group in project closure as the members of the project group started discussing the lack of goal attainment in the project. Reinforcement of outcome narratives also took place through the emergence of new cues about progress. An example is Spin-off narrative 1 where progress in the new projects acted as cues that reinforced the narrative in project closure. Another aspect of reinforcement was that some failure narratives ( 1 and 2 ) merged into a new failure narrative (4). In this way, the interpretation of failure appeared to be quite 'sticky', as it endured even though other outcome narratives emerged. Balogun and Johnson (2005) found that negative interpretations of a change project appeared early and were reinforced in later stages because they led to 'counteracting change consequences'. If the project does not have structures that enable discussions that challenge such negative interpretations, they become a sort of self-fulfilling prophesy.

The second process in which intersubjective meaning was created we have labelled 'continuous interpretation and reinterpretation of goals'. Meetings seemed to be particularly important in this process because they offered time and space to collectively reflect about challenging project goals, discuss different views and assess preliminary project outcomes in all project phases. Even though different views of project goals and outcomes did not always become aligned through these discussions, they clearly represented examples of collective sensemaking as the actors interpreted and reinterpreted goals. The spin-off projects emerged from an acknowledgement that the project goals were too broad and ambitious and as such difficult to fulfil. In contrast to accepting failure, the action taken was to delimit goals and establish new projects. This was presented as laying the groundwork for future success in terms of goal attainment. In this way, the spin-off narratives serve as examples of the continuous interpretation and re-interpretation of goals and could be understood as a way to handle unanticipated outcomes (Balogun, 2006) or acknowledge ongoing changes when evaluating organizational change processes (Hughes, 2011). The success narrative that appears towards the end of the project is an example of how goals were reinterpreted by highlighting one of several project goals. The success narrative highlighted the most tangible of the three main goals of the project: the goal of ensuring budget balance. In this study, however, budget balance was a fragile state. In project execution, the lack of budget balance was an important cue for Failure narrative 3, and when we validated our findings in a middle manager meeting in September 2018, the budget balance was again a thing of the past.

While the spin-off projects illustrate action taken, the cycles of interpretation and action also involve inaction, such as in Failure narratives 1 and 2. These narratives emerged based on previous experiences of project work. Because the members of the project group had worked closely together before, their joint interpretations were influenced by results in other projects and in other circumstances. In this case, it led to an interpretation that because project work previously had resulted in nothing, some of the project group members questioned the usefulness of engaging much in this project. Such interpretations could reinforce failure narratives. 
Sensemaking processes are likely to enact 'a more ordered environment' (Maitlis \& Christianson, 2014, p. 64). In our study, the project participants managed to create some order through continuous interpretation and re-interpretation of goals. For example, they agreed on the need for improvement on several dimensions, but felt that it was better to narrow down and focus the goals in small projects rather than handling ambitious goals in one 'big' project. In this way, they were able to combine a wide variety of goals and projects into a comprehensive whole. However, our data also show that the participants did not manage to create order regarding the change outcomes. The competing co-existing outcome narratives in the project closure phase seem to represent a less ordered environment. In one sense, this is advantageous because we have been able to identify a broader picture of outcome narratives and thus acknowledged the complexity of goals in change projects in the public sector. At the same time, however, this paints a rather messy picture of several competing outcome narratives of the same project at various times. This underscores our argument that change project outcomes should be studied over time and not assessed at the end of the project. Contrary to Balogun (2006) and Balogun and Johnson (2004), who found that diverging understandings merge over time, we found that they persisted. This finding is more aligned with 'subverting' (Beigi, Callahan, \& Michaelson, 2019 , p. 454) as narratives 'misalign and cannot be easily reconciled'. We found an explanation for this in the structure of this particular project organization. The interpretation of cues and emergence of outcome narratives followed the organizational structures of the project (see Figure 2). This implies that the formal structures are powerful beyond the division of labour and coordination and affect the cues that different actors attend to and their interpretation of those cues. In this study, weak structures did not lead to a confrontation between the competing narratives. Instead of being confronted and negotiated, the outcome narratives were reinforced and remained in isolated pockets in the organization. However, constructing a shared understanding takes time and could have occurred after we stopped our data collection. A question for further research to examine is whether sensemaking processes do facilitate the merging of diverging understandings over time in situations with ambiguous, contested and continuous goals.

\section{Conclusion}

By exploring how and when outcome narratives were constructed in a public change project, we contribute to the understanding of change outcomes in three ways. First, a sensemaking perspective enhances our understanding of change project outcomes. If we restrict our understanding of change outcomes to final goal attainment, we explicitly exclude unanticipated outcomes of change (Hughes, 2011), such as spin-off projects. As our study shows, this is unfortunate because it excludes the possibility that sensemaking of outcomes is developed through continuous processes throughout the change, rather than merely at the end of the project.

Second, this implies that change project outcomes should be studied through longitudinal research designs and methodological triangulation. This makes it possible to trace sensemaking about change outcomes by different actors over time. We encourage further longitudinal studies to theorize how sensemaking processes unfold in relation to change outcomes.

Third, the creation of intersubjective meaning assumes that there are arenas where individuals and groups can discuss and test their interpretations. Thus, project structures can facilitate and/or inhibit intersubjective meaning construction. This is especially important when goals are ambiguous, contested and continuous and subject to political processes. In our study, there were weak structures for aligning different views. Outcome narratives could therefore persist, even though alternative outcome narratives were constructed by others at later points. This suggests that change outcome narratives are quite 'sticky'. This study illustrates that 'change agents need to engage with living stories' (Bryant \& Frahm, 2011, p. 797) and that outcome narratives could play an important part as political tools (Beigi, Callahan, \& Michaelson, 2019) in the processes 
of change. Thus, the sensemaking perspective directs our attention to power and politics (Hope, 2010).

Even though the longitudinal design and methods triangulation in this study are well suited for exploring the sensemaking of change project outcomes, the main limitation of the study is that it is based on a single case. We argue that case studies provide thick descriptions of sensemaking processes and encourage more case studies of change project outcomes in the public and private sectors to complement and challenge the findings of this study.

This study has some practical implications for managers regarding the assessment of change project outcomes. Organizations should carefully consider when to draw conclusions about change outcomes because sensemaking of change outcomes seems to emerge in different phases and evolve over time. In addition, managers should be aware that goal attainment is not the only cue that individuals attend to when constructing outcome narratives. Managers should also establish structures that enable actors with different views to voice their understandings and to engage with each other. This could facilitate awareness of different change project outcome narratives that exist as well as collective sensemaking of change outcomes.

Acknowledgements. The authors wish to acknowledge the helpful comments from reader Mark Hughes on previous versions of this work. We thank the two anonymous reviewers for constructive suggestions in the development of this paper.

\section{References}

Anzola-Román, P., Bayona-Sáez, C., \& García-Marco, T. (2019). Profiting from collaborative innovation practice: Identifying organizational success factors along the process. Journal of Management \& Organization, 25(2), 239-262.

Armenakis, A. A., \& Bedeian, A. G. (1999). Organizational change: A review of theory and research in the 1990s. Journal of Management, 25(3), 293-315.

Bakari, H., Hunjra, A. I., \& Niazi, G. S. K. (2017). How does authentic leadership influence planned organizational change? The role of employees' perceptions: Integration of theory of planned behavior and Lewin's three step model. Journal of Change Management, 17(2), 155-187.

Balogun, J. (2006). Managing change: Steering a course between intended strategies and unanticipated outcomes. Long Range Planning, 39(1), 29-49.

Balogun, J., \& Johnson, G. (2004). Organizational restructuring and middle manager sensemaking. Academy of Management Journal, 47(4), 523-549.

Balogun, J., \& Johnson, G. (2005). From intended strategies to unintended outcomes: The impact of change recipient sensemaking. Organization Studies, 26(11), 1573-1601.

Beer, M., \& Nohria, N. (2000). Cracking the code of change. Harvard Business Review, 78(3), 133-141.

Beigi, M., Callahan, J., \& Michaelson, C. (2019). A critical plot twist: Changing characters and foreshadowing the future of organizational storytelling. International Journal of Management Reviews, 21(4), 447-465.

Brunsson, N. (2007). Mechanisms of hope. Maintaining the dream of the rational organization. Kristianstad, Sweden: Liber.

Bryant, M., \& Frahm, J. (2011). 'Kill Bill' and the change agent: A multi-genre approach to organizational stories. Journal of Management \& Organization, 17(6), 797-811.

Bryman, A., \& Bell, E. (2015). Business research methods. Oxford: Oxford University Press.

Buchanan, D., Fitzgerald, L., Ketley, D., Gollop, R., Jones, J. L., Lamint, S. S., Neath, A., \& Whitby, E. (2005). No going back: A review of the literature on sustaining organizational change. International Journal of Management Reviews, 7, 189-205.

Buchanan, D. A., Addicot, R., Fitzgerald, L., Ferlie, E., \& Baeza, J. I. (2007). Nobody in charge: Distributed change agency in health care. Human Relations, 60(7), 1065-1090.

Davis, K. (2014). Different stakeholder groups and their perception of project success. International Journal of Project Management, 32(2), 189-201.

Denis, J. L., Langley, A., \& Rouleau L. (2005). Rethinking leadership in public organizations. In E. Ferlie, L. Lynn \& C. Pollitt (Eds.), The Oxford handbook of public management (pp. 446-467). Oxford: Oxford University Press.

Doyle, M. T., Claydon, T., \& Buchanan, D. (2000). Mixed results, lousy process: The management experience of organizational change. British Journal of Management, 11(Special Issue), S59-S80.

Easterby-Smith, M., Thorpe, R., \& Lowe, A. (2002). Management research - An introduction. London: SAGE Publications Ltd.

Fincham, R. (2002). Narratives of success and failure in systems development. British Journal of Management, 13(1), 1-14.

Forssell, R. M., Fred, M., \& Hall, P. (2013). Projectification as a response to political demands for collaboration: A study of projects in the City of Malmö. Scandinavian Journal of Public Administration, 17(2), 37-59. 
Gioia, D. A., Corley, K. G., \& Hamilton, A. L. (2013). Seeking qualitative rigor in inductive research: Notes on the Gioia methodology. Organization Research Methods, 16(1), 15-31.

Hope, O. (2010). The politics of middle management sensemaking and sensegiving. Journal of Change Management, 10(4), 195-215.

Hughes, M. (2011). Do 70 per cent of all organizational change initiatives really fail? Journal of Change Management, 11(4), 451-464.

Hughes, M. (2016). Leading changes: Why transformation explanations fail. Leadership, 12(4), 449-469.

Jacobs, R. L. (2002). Institutionalizing organizational change through cascade training. Journal of European Industrial Training, 26, 177-182.

Kloppenborg, T., \& Opfer, W. (2002). The current state of project management research: Trends, interpretations, and predictions. Project Management Journal, 33(2), 5-18.

Langley, A. (1999). Strategies for theorizing from process data. Academy of Management Review, 24(4), 691-710.

Maitlis, S. (2005). The social processes of organizational sensemaking. Academy of Management Journal, 48(1), 21-49.

Maitlis, S., \& Christianson, M. (2014). Sensemaking in organizations: Taking stock and moving forward. Academy of Management Annals, 8(1), 57-125.

Mantere, S., Schildt, H. A., \& Sillince, J. A. A. (2012). Reversal of strategic change. Academy of Management Journal, 55(1), 172-196.

Müller, R., \& Söderlund, J. (2015). Innovative approaches in project management research. International Journal of Project Management, 33(2), 251-253.

Pádár, K., Pataki, B., \& Sebestyén, Z. (2017). Bringing project and change management roles into sync. Journal of Organizational Change Management, 30(5), 797-822.

Papke-Shields, K. E., Beise, C., \& Quang, J. (2010). Do project managers practice what they preach, and does it matter to project success? International Journal of Project Management, 28(7), 650-662.

Patton, M. Q. (2015). Qualitative research \& evaluation methods (4th ed.). Thousand Oaks, CA: SAGE.

Pettigrew, A. M. (1990). Longitudinal field research on change: Theory and practice. Organization Science, 1(3), $267-292$.

Pettigrew, A. M., Woodman, R. W., \& Cameron, K. S. (2001). Studying organizational change and development: Challenges for future research. Academy of Management Journal, 44(4), 697-713.

PMI (Project Management Institute) (2013). A guide to the project management body of knowledge (PMBOK ${ }^{\circledR}$ Guide) (5th ed.). Newton Square, PA: PMI.

Pollack, J. (2017). Change management as an organizational and project capability. In S. Sankaran, R. Müller \& N. Drouin (Eds.), Cambridge handbook of organizational project management (pp. 236-249). Cambridge: Cambridge University Press.

Rosenbaum, D., More, E., \& Steane, P. (2017). A longitudinal qualitative case study of change in nonprofits: Suggesting a new approach to the management of change. Journal of Management \& Organization, 23(1), 74-91.

Sage, D., Dainty, A., \& Brookes, N. (2013). Thinking the ontological politics of managerial and critical performativities: An examination of project failure. Scandinavian Journal of Management, 29(3), 282-291.

Sage, D., Dainty, A., \& Brookes, N. (2014). A critical argument in favor of theoretical pluralism: Project failure and the many and varied limitations of project management. International Journal of Project Management, 32(4), 544-555.

Schoper, Y. G., Wald, A., Ingason, H. T., \& Fridgeirson, T. V. (2018). Projectification in Western economies: A comparative study of Germany, Norway and Iceland. International Journal of Project Management, 36(1), 71-82.

Singh, S., Corner, P., \& Pavlovich, K. (2007). Coping with entrepreneurial failure. Journal of Management \& Organization, 13 (4), 331-344.

Söderlund, J. (2012). Styrning, tid och kreativa project [control, time and creative projects]. In J. Söderlund \& F. Tell (Eds.), Styrning: med projekt och kunskap i fokus [control: With a focus on projects and knowledge] (pp. 177-203). Lund: Studentlitteratur.

Sonenshein, S. (2010). We're changing or are we? Untangling the role of progressive, regressive, and stability narratives during strategic change implementation. Academy of Management Journal, 53(3), 477-512.

Thomas, J., George, S., \& Rose, R. (2016). Deciphering value discourse's role in explaining the persistent perception of change failure. Journal of Change Management, 16(3), 271-296.

Vaara, E. (2002). On the discursive construction of success/failure in narratives of post-merger integration. Organization Studies, 23(2), 211-248.

Vaara, E., Sonenshein, S., \& Boje, D. (2016). Narratives as sources of stability and change in organizations: Approaches and directions for future research. Academy of Management Annals, 10(1), 495-560.

Weick, K. (1995). Sensemaking in organizations. Thousand Oaks, CA: Sage Publications.

Dr. Grete Hagebakken is an associate professor at The School of Business and Economics at UiT The Arctic University of Norway. She obtained her $\mathrm{PhD}$ in political science from UiT. Her research interests include organizational change and project management in the public sector. 
Dr. Trude Høgvold Olsen is an associate professor at The School of Business and Economics at UiT The Arctic University of Norway. She obtained her PhD in strategy and management from NHH - Norwegian School of Economics. Her research interests include organizational change and management in hybrid organization.

Dr. Elsa Solstad is a professor at The School of Business and Economics at UiT The Arctic University of Norway. She obtained the degree Dr. Oecon in management control from The Business School at Nord University, Norway. Her research interests include management control and management in hybrid organizations.

Cite this article: Hagebakken G, Olsen TH, Solstad E (2020). Success or failure? Making sense of outcomes in a public sector change project. Journal of Management \& Organization 1-17. https://doi.org/10.1017/jmo.2020.19 